
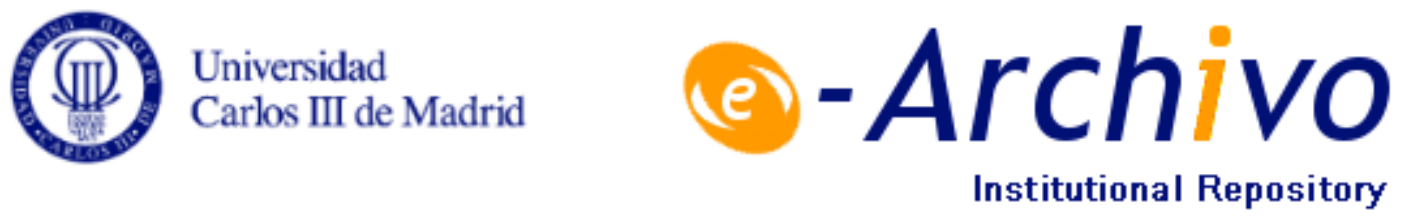

This is a postprint version of the following published document:

Albarrán, P., Carrasco, R. and Ruiz-Castillo, J. (2017). Are migrants more productive than stayers? Some evidence for a set of highly productive academic economists. Economic Inquiry, v. 55, n. 3, pp. 1308-1323. Available in: https://doi.org/2010.1111/ecin.12430

(C) Wiley 


\title{
ARE MIGRANTS MORE PRODUCTIVE THAN STAYERS? SOME EVIDENCE FROM A SET OF HIGHLY PRODUCTIVE ACADEMIC ECONOMISTS
}

\author{
PEDRO ALBARRÁN, RAQUEL CARRASCO and JAVIER RUIZ-CASTILLO*
}

\begin{abstract}
This article compares the average productivity of migrants (who work in a country different from their country of origin) and stayers (whose entire academic career takes place in their country of origin) in a set of 2,530 highly productive economists that work in 2007 in a selection of the top 81 Economics departments worldwide. The main findings are the following two. First, productivity comparisons depend on the cohort and the type of department. For example, in the top U.S. departments, foreigners are more productive than stayers only among older individuals; in the bottom U.S. departments, this is the case for both cohorts, while in the other countries the productivity of foreigners and stayers is indistinguishable for both cohorts. Second, when we restrict our attention to an elite consisting of economists with above average productivity, all productivity differences between migrants and stayers in the United States vanish. As our analysis depends on observational data in which the migration decision is not exogenously identified, our estimates have a descriptive rather than a causal interpretation. However, our results are very robust to the treatment of the elite, the partition into several department categories, and the definition of the cohorts and the productivity notion. (JEL J61)
\end{abstract}

\section{INTRODUCTION}

In all sciences, researchers originate from many countries. However, when we focus on the most productive and influential researchers we observe that a large contingent of scientists working in the top U.S. research institutions have obtained their first college degree in their country of origin. Understandably, this situation can be described as a case of what Hunter, Oswald, and Charlton (2009) calls the elite brain drain-a

* Albarrán acknowledges financial support from the Spanish MEC through grants ECO2009-11165 and ECO2011-29751, and Carrasco and Ruiz-Castillo through grants No. ECO2012-31358 and ECO2014-55953-P, respectively, as well as grant MDM 2014-0431 to their Departamento de Economía. Conversations with Jesús Fernández-Huertas are gratefully acknowledged. Two anonymous referee reports and many suggestions by Dr. Abigail Wozniak, coeditor of Economic Inquiry, dramatically improved the original version of this article. All remaining shortcomings are the sole responsibility of the authors.

Albarrán: Professor, Departamento de Fundamentos del Análisis Económico, Universidad de Alicante, Alicante, Spain. Phone +34 9659034 00, E-mail albarran@ua.es

Carrasco: Professor, Departamento de Economía, Universidad Carlos III, Madrid, Spain. Phone +34 62495 83, E-mail rcarras@eco.uc3m.es

Ruiz-Castillo: Professor, Departamento de Economía, Universidad Carlos III, Madrid, Spain. Phone 349162495 88, E-mail jrc@eco.uc3m.es worrisome phenomenon from the point of view of the sending countries. ${ }^{1}$

Based on a sample of highly productive academic economists, our main aim is to study whether the productivity of foreigners is greater or not than the productivity of stayers - who are those who study and work in their country of origin - both in the United States and in other countries with at least one department in the sample (Other Sample Countries or OSC hereafter). This is an interesting question for several reasons. First, brain drain is an important phenomenon in all sciences. The share of economists who are migrants in our dataset is $41.1 \%$ in the United

1. For the economics of immigration, see Borjas (1999) and Stark (2005), and for a survey of four decades of economics research on the brain drain, see Doquier and Rapoport (2012). Specifically, for the elite brain drain, see inter alia Stephan and Levin (2001), Laudel (2003, 2005), Bauwens, Mion, and Thisse (2008), and Panaretos and Malesios (2012).

\section{ABBREVIATIONS}

EU: European Union

OLS: Ordinary Least Squares

OSC: Other Sample Countries

RW: Rest of the World 
States and $38.5 \%$ in the OSC. For the understanding of the academic sector, we would like to know whether migrants are more productive than stayers. Second, this question is relevant for the design of immigration/emigration policies. For example, from a world welfare point of view, if it were the case that migrants are generally more productive than stayers, then there are reasons to defend the validity of policies aimed at facilitating increased brain exchange across countries (Franzoni, Scellato, and Stephan 2014). Naturally, as we will see in the discussion section, this is not the only point of view to be considered.

The results in the literature concerning the existence of productivity differences between migrants and nationals in the U.S. academic sector are mixed. Independently of the fact that different studies use different methodologies, as well as different productivity measures for scientists in different fields during different time periods, there are also important differences in the characteristics of the group to whom migrants are compared. For example, Hunter, Oswald, and Charlton (2009) study a small sample of 138 highly cited researchers writing in physics journals between 1981 and 1999. Using a simple formal model, their main conclusion is that, due to low mobility costs, the distribution of talent can be expected to be similar across different countries, so that foreigners who move to the United States go on to be neither more nor less distinguished than American-born elite physicists. This contradicts the results from two important contributions whose datasets consist of more than 2,500 Ph.D. economists working in the United States (McDowell and Singell 2000), or more than 14,000 retrospective questionnaires in several sciences (Franzoni, Scellato, and Stephan 2014). Both studies find that, after controlling for the endogeneity of the migration decision, migrant scientists exhibit superior performance. ${ }^{2}$

Our contribution to this literature is twofold. First, we observe the existence of department effects in the United States, in the sense that when we partition the U.S. departments into several categories according to their prestige - say, top, intermediate, and bottom categories - the average productivity of economists working in each category is hierarchically ordered. Department

2. The same conclusion is reached by Ruhose et al. (2015) for 565 high-skilled German immigrants versus 289,538 high-skilled U.S. natives. However, rather than Ph.D. holders working in the U.S. academic sector, the high-skilled in this paper are individuals with a B.A. or higher degree who work in any type of full-time job in the United States. effects are not explored by McDowell and Singell (2000) or Franzoni, Scellato, and Stephan (2014). In our case, controlling for fixed department effects has no effect. However, when we make productivity comparisons between migrants and stayers within department categories, we discover that the situation is different in top and bottom U.S. institutions. Second, consider the possibility of restricting the attention to some subset of researchers in the upper tail of the ordered individual productivity distribution. We refer to such subset as the elite. In this paper, we establish that when we make such a move in Hunter, Oswald, and Charlton's (2009) model, the productivity of elite migrants converges to the productivity of elite stayers. We test this prediction with our data.

Our dataset consists of 2,530 economists that work in 2007 in the top 81 Economics departments worldwide according to the Econphd.net (2004) rankings. Not surprisingly, 52 of the 81 departments are located in the United States. There are only 11 OSC with at least one of the remaining 29 non-U.S. departments in the sample. We measure individual productivity in terms of a quality index that weights the number of publications from the beginning of everyone's career up to 2007 in four journal classes. We use different weighting schemes leading to different productivity measures.

As is well known, the unobservable ability of individuals is correlated both to migration and to performance. But our productivity comparisons are obtained with retrospective data concerning economists' mobility and aggregate productivity up to 2007. Thus, in the absence of information for correcting the typical positive selection into migration among the high skilled, the endogeneity of individuals' locational choice makes a causal interpretation of our results impossible. In this situation, we are restricted to searching for robust correlations capturing some new stylized facts worth investigating further in economics and other scientific disciplines.

Our preferred specification consists of the double partition of departments into three categories - top U.S. departments, bottom U.S. departments, and OSC departments - and individuals into two cohorts of young and older people. In this specification, we make six productivity comparisons between foreigners and stayers. Together with demographic variables, we control for a relatively rich set of career variables, namely, the university where each individual earns her B.A., and her Ph.D., as well as the university where each holds her first job. 
Moreover, for the reasons explained before, we find it interesting to make all of our productivity comparisons for the entire population consisting of 2,530 economists, and an elite consisting of 833 individuals with above average productivity.

Our main results are the following four. First, in the top 25 U.S. departments, the productivity of foreigners in the total sample is greater than the productivity of stayers only among the older individuals. Among the young, the productivity of the two groups is indistinguishable. Second, in the bottom 27 U.S. departments the situation is very different. The key feature is the very low productivity of both young and older stayers in the total sample. Thus, migrants are more productive than stayers in both cohorts in this sample. Third, in agreement with our extension of Hunter, Oswald, and Charlton's (2009) model, all productivity differences between foreigners and stayers in the United States vanish in the elite. Finally, in the OSC departments, foreigners and stayers are equally productive in the two cohorts. This is the case both in the total sample and the elite.

A remarkable aspect of these findings is that they are robust in the following four directions: (1) the partition of the 81 departments into three or more categories, (2) the treatment of the elite, (3) the definition of the two cohorts, and (4) the weighting scheme used in the construction of the productivity measure.

The rest of the article consists of four sections. Section II presents the data, as well as some descriptive statistics. Section III describes the sequence of estimates leading to our preferred specification, and presents the key empirical results comparing the productivity of migrants and stayers in the total sample and the elite controlling for demographics and career variables. Section IV discusses the robustness and a plausible interpretation of the results. Finally, Section V offers some concluding comments. Appendix S1, Supporting Information, includes some statistical material, and an extension of Hunter, Oswald, and Charlton's (2009) model. To save space, we will refer to other statistical material in the Working Paper version of this article, Albarrán et al. (2016).

\section{DATA, THE MEASUREMENT OF PRODUCTIVITY, AND THE ELITE NOTION}

\section{A. The Data}

In this subsection, we briefly describe the dataset used in this article. In the first place, we select the top 81 departments worldwide according to the Econphd.net (2004) university rankings. This ranking is built upon the publications in the period 1993-2003 in the top 63 Economics journals in the Kalaitzidakis, Mamuneas, and Stengos (2003) weighted journal ranking, where the weights reflect journal citation counts adjusted for factors such as the annual number of pages and the age of the journal (for further methodological details, see Econphd.net rankings 2004). ${ }^{3}$

Searching in the 81 departmental web pages in 2007, we found a total of 2,705 economists with the minimum information we require for each individual: nationality, university where a Ph.D. is obtained, age, and publications in the periodical literature up to 2007. The information concerning the country of birth is seldom available. Therefore, we assign the nationality in terms of the country where each individual obtains a B.A. or an equivalent first college degree. ${ }^{4} \mathrm{Sim}-$ ilarly, since an individual's age is not generally available we use the academic age, namely, the number of years elapsed since earning a Ph.D. (or equivalent degree) up to 2007 as a measure of experience.

\section{B. The Measurement of Individual Productivity}

We take information available in Internet (personal web pages, RePEc, Publish or Perish, etc.) on publications up to 2007 of these 2,705 people. Because of budgetary restrictions, our information on productivity suffers from two limitations. First, the article count in our dataset made no distinction between single and multiple authorship. Consequently, no correction for coauthorship could be implemented. Nevertheless, there is evidence that the average number of authors per article in Economics \& Business in 2003-2011 is 1.8 , whereas the mean and standard deviation for 30 broad scientific disciplines are 3.1 and 1.1,

3. We have compared this list with the first 81 Economics departments listed in three other equally acceptable university rankings. The main conclusion is that, apart from differences in the order in which each institution appears in the various rankings, our list has between 70 and 73 departments in common with each of the three other lists (for further details, see Albarrán, Carrasco, and Ruiz-Castillo 2014). However, the Econphd.net rankings (2004) department ranking is also used in Oyer (2006).

4. Consider the case of a foreigner earning her B.A. in a U.S. institution who works in the United States in 2007. She will be classified as a U.S. stayer. Quite apart from the fact that we do not have the means to learn about her true nationality, in so far as this person does not consume national resources in her college education, there are reasons to classify her as a U.S. stayer. 
respectively (Ruiz-Castillo and Costas 2015). Therefore, under the assumption that the assignment of equal responsibility for coauthored publications is a more acceptable assumption when the number of authors per publication is small, our practice of assigning full credit for all publications to each author, independently of whether they are coauthored or not, is a lesser problem in our case. Second, although we know the journal where each article is published, it was impossible to search for the citation impact achieved by every article. Therefore, we are constrained to measuring individual productivity as a function of the total number of publications per person over her academic career up to 2007.

In every science, there is broad agreement about the different merit associated to publishing in a reduced number of top journals, a larger set of excellent field journals, or the remaining international or local journals. Although any specific classification will always be controversial, a consensus on how to weight the different journal classes in order to reach a scalar measure of productivity is possibly even harder to reach.

Starting from the top 63 journals in Kalaitzidakis, Mamuneas, and Stengos's (2003) journal ranking, and taking also into account the rankings in Lubrano et al. (2003), and Kodrzycki and Yu (2006), in this paper we distinguish between four journal classes. ${ }^{5}$ In our preferred weighting scheme, the four classes are assigned weights equal to $40,15,7$, and 1 point, respectively. The resulting quality index is denoted by $Q$. Being aware that this option might be objected to for placing too much weight on top journals, we study the robustness of our findings using two other productivity indices. The first one, denoted by $Q^{\prime}$, assigns weights equal to $20,10,5$, and 1 point to the four classes. The last index, denoted by $P$, weights equally all classes, that is, it measures individual productivity as the total number of publications. Table A in Appendix S1 includes the listing of the 81 departments, together with

5. Classes A, B, and C consist of 5, 34, and 47 journals, while class D consists of any other journal. Class A includes the American Economic Review, Econometrica, Journal of Political Economy, Quarterly Journal of Economics, and Review of Economic Studies. By way of example, the following 12 journals are in class B: Economic Journal, Games and Economic Behavior, International Economic Review, Journal of Econometrics, Journal of Economic Growth, Journal of Economic Theory, Journal of Finance, Journal of Labor Economics, Journal of Monetary Economics, Journal of Public Economics, Rand Journal of Economics, and Review of Economics and Statistics. See Albarrán, Carrasco, and RuizCastillo (2014) for further details concerning this construction, including the listing of all journals in classes B and C. information for each institution concerning the number of faculty members (including Emeritus Professors), the number of people without publications, the remaining scholars' publications in classes $\mathrm{A}$ to $\mathrm{D}$, and the department value of indices $Q, Q^{\prime}$, and $P$. The OSC consist of eight European countries (UK, the Netherlands, Spain, Sweden, France, Germany, Belgium, and Denmark), and three non-European countries (Canada, Israel, and China).

\section{The Total Sample Versus the Elite}

Of the 2,705 economists in our dataset, there are 175 faculty members without any publications at all (typically because they are at the beginning of their career). In line with the previous literature on individual productivity, we focus on what we call the total sample consisting of the 2,530 faculty members with at least one publication.

The following two characteristics of productivity distributions are worth noting. Consider index $Q$. First, the 2,530 individuals in the total sample are very productive: average productivity is 307.3 quality points per capita, equivalent to more than seven articles of class A or about 20 articles of class B. Alternatively, the average quality index is 16.1 per year during an academic life (the period from the first year after receiving a Ph.D. up to 2007), a quantity that can be compared with the 15 points assigned to one article in class B. Second, the distribution of individual productivity is highly skewed. As many as $36.9 \%$ of the sample has no class A publication, while $25 \%$ published once or twice, and the remaining $38.1 \%$ published three or more times in the top journal class. However, the average productivity is 17 percentage points above the median, and the top $10 \%$ account for $40 \%$ of all quality points. ${ }^{6}$ In this context, we find it useful to define the elite as consisting of the 833 individuals with above average productivity. ${ }^{7}$

Productivity distributions $Q^{\prime}$ and $P$ are very similar to distribution $Q$. In particular, the mean productivity of $Q^{\prime}$ is equivalent to more than nine

6. Interestingly, these figures are of the same order of magnitude as those found in Ruiz-Castillo and Costas (2015) who study the productivity of 17.2 million authors in 30 broad scientific fields with publications in the period 2003-2011.

7. Table B in the Appendix in Albarrán, Carrasco, and Ruiz-Castillo (2014) lists all members of this elite (plus equally productive Fellows of the Econometric Society who are active in 2007 but not working in the 81 sample departments), including their $Q$ value, their nationality, and the university to which they are associated in 2007. 
articles in class $\mathrm{A}$, whereas the mean productivity of $P$ is equal to 27 publications. However, since the two new distributions exhibit essentially the same skewness as distribution $Q$, if we define the elite notion as we did for distribution $Q$ the corresponding sizes are of the same order of magnitude as before: 843 for index $Q^{\prime}$, and 835 for index $P$.

\section{EMPIRICAL RESULTS}

\section{A. Specification Issues in the Total Sample}

In this subsection, we introduce our preferred specification for the total sample when individual productivity is measured by the $Q$ index. Given the high skewness of the individual productivity distribution, the dependent variable in the sequel is always the log of the $Q$ index.

We proceed in three steps. First, we analyze the important role of demographic variables (experience and gender). Second, we focus attention on the comparison of the productivity of foreigners and stayers in the United States and the OSC, controlling for two types of variables: department effects in the United States, and a number of other career variables, namely, the university where each individual earned her B.A. and her Ph.D., as well as the university where she held her first job. Third, we study how best to interact the migrant/stayer condition with department effects and vintage variables. The definition of all explanatory variables will be presented in due order below. Descriptive statistics for the total sample are included in the left-hand panel in Table 1A, where the reference group for any set of dummy variables is marked with an asterisk.

Demographic Variables. As indicated in the Introduction, our measure of aggregate productivity up to 2007 favors older people. Together with the variable Experience (or Exp hereafter), and $(\operatorname{Exp})^{2}$, we introduce a dummy variable, Young, that takes the value one for young people, defined as those who earn a Ph.D. at most 20 years before 2007. Taking into account that the median age for finishing a Ph.D. is approximately 30 (Scott and Siegfried 2008), young people in our sample are those with at most 50 years of age in 2007. They represent approximately half of the total sample. To account for the possibility that the productivity effect of one more year of academic experience is different for young and older individuals, our specification includes
TABLE 1

Explanatory Variables and Descriptive Statistics

\begin{tabular}{|c|c|c|}
\hline & $\begin{array}{c}\text { Total } \\
\text { Sample }\end{array}$ & Elite \\
\hline \multicolumn{3}{|l|}{ (A) } \\
\hline \multicolumn{3}{|l|}{ Demographic variables } \\
\hline Mean years of experience $(S D)$ & $18.8(12.4)$ & $27.2(10.4)$ \\
\hline Young ${ }^{\mathrm{a}}$ & 0.501 & 0.287 \\
\hline Young ${ }^{\mathrm{b}}$ & 0.458 & 0.131 \\
\hline Young ${ }^{\mathrm{c}}$ & 0.671 & 0.439 \\
\hline Females & 0.140 & 0.054 \\
\hline \multicolumn{3}{|l|}{ Career variables } \\
\hline B.A. = Top 10 U.S. & 0.118 & 0.176 \\
\hline B.A. $=$ Next 15 U.S. & 0.057 & 0.084 \\
\hline B.A. $=$ Next 27 U.S. & 0.053 & 0.059 \\
\hline B.A. = Other U.S. & 0.159 & 0.184 \\
\hline B.A. $=\mathrm{EU}^{\mathrm{d} *}$ & 0.375 & 0.266 \\
\hline B.A. $=$ RW $^{\mathrm{e}}$ & 0.238 & 0.231 \\
\hline Ph.D. = Harvard \& MIT & 0.139 & 0.214 \\
\hline Ph.D. = Other top 10 U.S. & 0.296 & 0.328 \\
\hline Ph.D. $=$ Next 15 U.S. & 0.164 & 0.160 \\
\hline Ph.D. = Next 27 U.S. & 0.072 & 0.070 \\
\hline Ph.D. = Other U.S. & 0.021 & 0.013 \\
\hline Ph.D. $=\mathrm{EU}^{\mathrm{d} *}$ & 0.269 & 0.176 \\
\hline Ph.D. $=\mathrm{RW}^{\mathrm{e}}$ & 0.039 & 0.039 \\
\hline First job = Top 10 U.S. & 0.212 & 0.349 \\
\hline First job $=$ Next 15 U.S. & 0.145 & 0.167 \\
\hline First job $=$ Next 27 U.S. & 0.143 & 0.119 \\
\hline First job = Other U.S. & 0.068 & 0.050 \\
\hline First job $=E U^{d} *$ & 0.272 & 0.192 \\
\hline First job $=\mathrm{RW}^{\mathrm{e}}$ & 0.155 & 0.121 \\
\hline First job $=$ Missing & 0.005 & 0.001 \\
\hline $\begin{array}{l}\text { Current job }=\text { Top } 25 \text { U.S. } \\
\text { departments }\end{array}$ & 0.354 & 0.549 \\
\hline $\begin{array}{l}\text { Current job = Last } 27 \text { U.S. } \\
\text { departments }\end{array}$ & 0.266 & 0.218 \\
\hline $\begin{array}{c}\text { Current job }=\text { OSC } \\
\text { departments } *\end{array}$ & 0.380 & 0.233 \\
\hline \multicolumn{3}{|l|}{ Movers and stayers } \\
\hline U.S. brain circulation & 0.003 & 0.006 \\
\hline U.S. brain drain & 0.255 & 0.281 \\
\hline U.S. stayers & 0.362 & 0.480 \\
\hline OSC brain circulation & 0.071 & 0.059 \\
\hline OSC brain drain & 0.147 & 0.068 \\
\hline OSC stayers* & 0.162 & 0.106 \\
\hline Number of observations & 2,530 & 833 \\
\hline
\end{tabular}

(B)

U.S. brain circulation $\quad 0.003$

USTop 25, foreigners, young $\quad 0.106$

USTop 25, foreigners, old $\quad 0.046$

USTop 25, stayers, young $\quad 0.081$

USTop 25, stayers, old $\quad 0.118$

USLast 27, foreigners, young $\quad 0.073$

USLast 27, foreigners, old $\quad 0.029$

USLast 27, stayers, young $\quad 0.054$

USLast 27, stayers, old $\quad 0.109$

OSC brain circulation $\quad 0.071$

OSC foreigners, young $\quad 0.118$

OSC foreigners, old $\quad 0.029$

OSC stayers, young $\quad 0.101$

OSC stayers, old* $\quad 0.062$

Total number of observations $\quad 2,530$

Percentage of young

USTop 25, foreigners $\quad 0.698$

USTop 25, stayers $\quad 0.409$

USLast 27, foreigners $\quad 0.715$

USTop 25, stayers $\quad 0.328$ 
TABLE 1

Continued

\begin{tabular}{lcc}
\hline & $\begin{array}{c}\text { Total } \\
\text { Sample }\end{array}$ & Elite \\
\hline OSC brain circulation & 0.657 & \\
OSC foreigners & 0.806 & \\
OSC stayers & 0.620 \\
Total sample & 0.501 & \\
\hline
\end{tabular}

Notes: The total sample consists of faculty members with at least one publication in the top 81 departments worldwide according to the Econphd (2004) university ranking, while the elite consists of individuals with above average productivity. Movers \& stayers when an individual is Young if Experience $\leq 20$, and Old if Experience $>20$.

andividuals with less than 20 years after earning a Ph.D. $\sim$ less than 50 years of age.

${ }^{\mathrm{b}}$ Individuals with less than 15 years after earning a Ph.D. $\sim$ less than 45 years of age.

${ }^{\mathrm{c}}$ Individuals with less than 24 years after earning a Ph.D. $\sim$ less than 54 years of age.

${ }^{\mathrm{d}} E U$ stands for the 15 countries in the European Union before the 2004 accession.

${ }^{\mathrm{e}} R W$ stands for the Rest of the World, namely, countries outside the United States and the EU.

${ }^{*}$ Reference group in the regressions.

an interaction between the cohort and the age variables. Finally, the dummy variable Female takes the value one for females. Thus, model 1 is the following:

$$
\begin{aligned}
& \log Q=\alpha_{0}+\alpha_{1} \operatorname{Exp}+\alpha_{2} \operatorname{Exp}^{2} \\
& +\alpha_{3}(\text { Exp } \times \text { Young })+\alpha_{4}\left(\operatorname{Exp}^{2} \times \text { Young }\right) \\
& +\alpha_{5} \text { Young }+\alpha_{6} \text { Female }+\epsilon .
\end{aligned}
$$

Regression results for this model, as well as age, cohort, and gender effects are in the left-hand panel of Table 2.

The six variables of the model are highly significant. In agreement with human capital models, we find a humped-shaped progression of individual research productivity with academic age because the stock of human capital needs to be built up at the beginning of the career while, due to the finiteness of life, no new investment offsets depreciation and net investment declines (eventually) over time. Moreover, the young are more productive than the old, and the productivity gap of the young increases with experience. Finally, females - representing 14\% of the total sample-are $57.9 \%$ less productive than males. At any rate, experience, cohort, and gender effects account for a large proportion of the variance: the adjusted $R^{2}$ in model 1 is $0.44 .^{8}$

8. Interestingly, "Years since Ph.D. accounted for $43 \%$ of the variance of $\log$ (total citations), $48 \%$ of the variance in
In order to test how robust age and cohort effects are to the cohort definition, we experiment with two other specifications: the variable Young takes the value one when Exp is less than or equal to 15 or 24 , so that young people are individuals with at most 45 or 54 years of age in 2007 . The percentage of young people becomes $45.8 \%$ and $67.1 \%$, respectively (Table $1 \mathrm{~A}$ ). Regression results for the six variables in model 1 are in Table 3 in Albarrán, Carrasco, and Ruiz-Castillo (2016). Except for Young when $\operatorname{Exp} \leq 24$, all variables are again highly significant. Experience and gender effects are practically the same as before. The only difference concerns cohort effects: being young is somewhat more important than before for the smaller subset of young people in the second specification, whereas it becomes negative for the larger subset of young people in the third specification. Nevertheless, the productivity gap between young and older people increases with experience in all cases. Judging from the adjusted $R^{2}$, the importance of experience, cohort, and gender effects is as large as before.

In view of these results, we continue the analysis with the cohorts' original definition. Nevertheless, in Section IV.C we study the robustness of our key results with respect to alternative cohort specifications.

Foreigners Versus Stayers: A First Approximation. The 81 departments in the sample are classified into Top and Bottom institutions using the Econphd department ranking (Table A in Appendix S1). We begin by defining the former as the 25 top U.S. departments (that practically coincide with the top 25 departments in the world). Among the Bottom institutions, we distinguish between two categories: the last 27 U.S. departments, and the 29 non-U.S. departments located in the OSC. ${ }^{9}$ Group sizes are in Table 1A. We should emphasize that the two Bottom groups are heterogeneous categories with a large overlap in terms of the Econphd department

$\log (\mathrm{h}), 36 \%$ of the variance in $\log (\mathrm{e})$, and $54 \%$ of the variance in $\log \left(\mathrm{h}_{\mathrm{m}}\right)$ [e and $\mathrm{h}_{\mathrm{m}}$ are variants of the $\mathrm{h}$ index]" (Nosek et al. 2010, p. 1287).

9. Of course, which departments are in the "top 10," "top 25," or "last 27" at any moment is open to debate. Moreover, even if this classification is appropriate for the period 2004-2007, individual departments are likely to have changed positions over the period of this study prior to 2007. Therefore, it is advisable to take this partition as representative of "top" or "bottom" departments in general. 
TABLE 2

A Sequence of Exploratory Models for the Total Sample

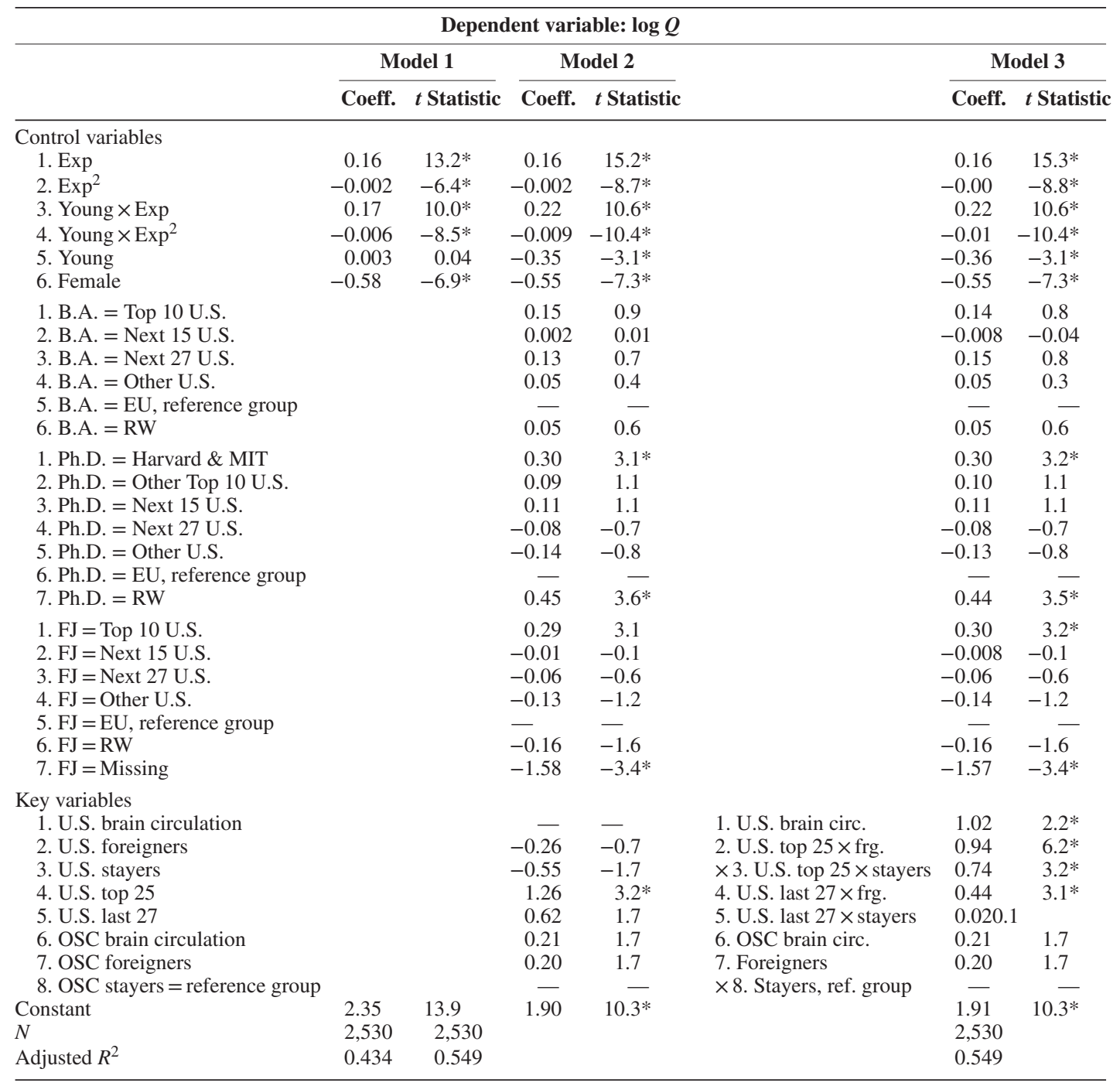

Notes: The total sample consists of faculty members with at least one publication in the top 81 departments worldwide according to the Econphd (2004) university ranking. In all cases, productivity is measured according to the $Q$ index, and an individual is Young if Experience $\leq 20$ and Old if Experience $>20$.

* Significant at the $95 \%$ confidence level.

ranking. ${ }^{10}$ It should be noted that in Section IV.B we explore the consequences of considering a partition into five department categories: on one hand, among the first 25 U.S departments we

10. In particular, the last 27 U.S. departments include nine institutions that range from positions 32 to 44 in the Econphd ranking, and 18 departments ranging from positions 51 to 78 , while the 29 OSC departments include four departments in the range 12 to 24 , seven departments ranging from positions 30 to 45 , and 18 departments ranging from positions 46 to 81 (Table A in Appendix S1). distinguish between the top 10 and the next 15 U.S. departments whereas, on the other hand, we distinguish between the departments in Canada and the UK and those in the remaining nine OSC.

Together with the brain drain, there is a second group of scientists who study and/or work abroad followed by a return to the home country - a phenomenon known as brain circulation. Such people return home with the human capital they would not have acquired if it were 
not for the possibility of temporary emigration. ${ }^{11}$ Therefore, it is convenient to partition individuals working in each of the two geographical areas in 2007 into three groups: brain drain, brain circulation - which will be referred to as movers - and stayers (Table 1A). We begin by comparing the productivity of foreigners and stayers in the two geographical areas controlling for the type of department in which they work in 2007 (dummy variables USTop25 and USLast27). Omitting all control variables, model 2 is the following:

$$
\begin{aligned}
& \text { Log } Q=\alpha_{0}+\beta_{1} \text { USForeigners } \\
& +\beta_{2} \text { USStayers }+\beta_{3} \text { OSCForeigners } \\
& +\delta_{1} \text { USTop } 25+\delta_{2} \text { USLast } 27+\epsilon
\end{aligned}
$$

where the constant includes OSC stayers. To test for the existence of department effects we specify the following hypothesis:

Between foreigners or stayers in USTop 25 and USLast 27, $\mathrm{H}_{0}: \delta_{1}-\delta_{2}=0$;

Between foreigners in USLast27 and OSC, $\mathrm{H}_{0}:\left(\delta_{2}+\beta_{1}\right)-\beta_{3}=0$;

Between stayers in USLast27 and OSC, $\mathrm{H}_{0}$ : $\delta_{2}+\beta_{2}=0$.

In turn, the key comparisons between the productivity of foreigners and stayers requires testing whether $\beta_{1}-\beta_{2}=0$ in the United States, and whether $\beta_{3}=0$ in the OSC.

Together with demographic variables, we include two dummy variables for the individuals in brain circulation ( $U S b c$ and $O S C b c$ ), as well as a set of dummy variables that capture the progression of economists through their undergraduate and graduate education to the first part of their academic career. Specifically, these variables capture the university where individuals obtain their B.A., their Ph.D., or where they held their first job. The distribution of the 2,530 economists in the sample according to these career variables is in Table 2 . In each case, we distinguish between different types of U.S. universities, universities in the European Union before the 2004 accession (EU hereafter), and universities from the Rest of the World (RW hereafter).

From the descriptive point of view, the following four comments are in order. First, brain circulation is a very small contingent in the United

11. For the brain circulation phenomenon, see inter alia Borjas and Bratsberg (1996), Grogger and Hanson (2013), and Kahn and MacGarvie (2016).
States $(0.3 \%$ of the total), but a larger one in the OSC $(7.1 \%)$. Otherwise, there are more stayers than foreigners in both areas. Second, U.S. graduate schools are very attractive for this set of highly productive economists. In particular, approximately $44 \%$ of them earned their Ph.D. at the ten top U.S. schools. Third, because some individuals returned home after earning their Ph.D., those holding a first job in the United States are almost 12 percentage points lower than those graduating there. Finally, after a reshuffling at the next stage, the number of people working in 2007 in the United States or in the European OSC increases somewhat, while the number of people working in the non-European OSC decreases. The end result is that only $38.7 \%$ of the sample is born in the United States, but $62.0 \%$ end up working there in 2007-a strong funneling effect toward the United States.

Regression results for model 2 are in the middle panel of Table $2 .{ }^{12}$ The following four points should be noted. First, because all USbc work in USTop25, the coefficient of the former cannot be identified. Second, among control variables all demographic variables are significant. Experience and cohort effects are very similar to those analyzed for model 1 (for details, see Table B.1 in Appendix I in Albarrán, Carrasco, and Ruiz-Castillo 2016). However, only three of the other control variables are significant: individuals having earned a Ph.D. in Harvard or MIT or the RW, or having had a first job in any of the ten top U.S. universities have a significantly greater productivity than the corresponding reference group. The inclusion of the 28 nondemographic dummy variables increases the adjusted $R^{2}$ from 0.436 to 0.549 . Third, as expected, the difference $\delta_{1}-\delta_{2}=0.6350$ is statistically significant $(p=0.000)$, indicating the existence of strong department effects in the United States. What about department effects between USLast27 and OSC? We find that the expressions $\left(\delta_{2}+\beta_{1}\right)-\beta_{3}=0.1627$ and $\delta_{2}+\beta_{2}=0.0717$ are not significantly different from zero ( $p$ values 0.119 and 0.749 ). This indicates that the productivity of economists in the last 27 U.S. departments and the 29 OSC departments is indistinguishable. Given the overlapping of the department rankings in the two groups (see note 10), this is not a surprising result.

The existence of department effects in the United States requires discussing whether higher

12. All regressions in the paper include clustered standard errors by the university where each individual works in 2007. 
performing universities contribute to the productivity of individual researchers and/or whether they simply attract more productive individuals. As indicated in the Introduction, our data do not allow us to address this issue. However, the results of the literature on the existence of spillover effects are clearly negative (Azoulay, Zivin, and Wang 2010; Borjas and Doran 2015; Dubois, Rochet, and Schlenker 2014; Han Kim, Morse, and Zingales 2009; Waldinger 2012). In particular, in their important contribution to the decline of spillover effects in the top 25 U.S. university economics and finance departments over the 1970-2001 period, Han Kim, Morse, and Zingales (2009) conclude that the loss of spillover effects among elite universities is due to advances in communication technology. ${ }^{13}$ Naturally, the decline of spillover effects is compatible with the permanence of department effects. As Han Kim, Morse, and Zingales (2009) indicate, "The difference in average individual productivity between the top 25 universities and the others has increased, not decreased, in the last three decades. Elite universities seem to attract and retain the most productive researchers, even though these universities do not make their faculty more productive" (p. 355). This is, of course, what we find in our dataset: highly productive economists tend to come together in institutions of high productivity and prestige in a hierarchically ordered manner. Han Kim, Morse, and Zingales (2009) argue that, on the supply side, top researchers agglomerate in institutions with prestigious undergraduate programs and in departments with high past research reputations. Such agglomeration could be due to the utility and the prestige of colocation with other creative minds. This, together with the role of meritocratic criteria and a reasonable degree of ability in hiring and promoting decisions on the demand side in a highly competitive market, help account for the existence of a clear hierarchical department structure, such as the one revealed in the Econphd department ranking and the two types of U.S. departments distinguished so far.

A final key question for us in model 2 is the comparison between the productivity of migrants and stayers. We find that the difference

13. It should be noted that the list of 25 departments in Han Kim, Morse, and Zingales (2009) includes our first 15 U.S. departments. Together with the University of British Columbia, located in Canada, three other of their departments appear between positions 16 to 20 in our U.S. ranking, while the remaining six appear in the positions $26,28,30,34,43$, and 46 of that ranking. $\beta_{1}-\beta_{2}=0.2910(p=0.117)$ and the coefficient $\beta_{3}(t$ value $=1.67)$ are not significantly different from zero, indicating that foreigners and stayers in the two geographical areas appear to be equally productive. This is exactly what we obtain when we maintain all control variables but omit department fixed effects in model 2: the difference $\beta_{1}-\beta_{2}=0.2831(p=0.120)$ and the coefficient $\beta_{3}(t$ statistic $=1.68)$ are not significantly different from zero (complete results for this intermediate specification between model 1 and model 2 are available on request). These results suggest that department effects and the migrant/stayer condition are uncorrelated. However, this is not the end of the story. In the next step, we explore what happens within each department category by including interactions between dummy variables for foreigners and stayers (Frg and Sty) and the partition of U.S. departments into the Top25 and the Last27.

Foreigners Versus Stayers: Final Specification. Omitting control variables, model 3 becomes:

$$
\begin{aligned}
& \log Q=\alpha_{0}+\beta_{1}(\text { USTop } 25 \times \text { Frg }) \\
& +\beta_{2}(\text { USTop } 25 \times \text { Sty })+\beta_{3}(\text { USLast } 27 \times \text { Frg })
\end{aligned}
$$$$
+\beta_{4}(\text { USLast } 27 \times \text { Sty })+\beta_{5}(\text { OSC } \times \text { Frg })+\epsilon
$$

where the constant includes OSC stayers. It should be noted that the proportion of migrants in the three department categories are the following: $42.8 \%$ in the top U.S. departments, $38.7 \%$ in the bottom U.S. departments, and $38.5 \%$ in the OSC. Regression results for model 3 are in the right-hand panel in Table 2. Key productivity comparisons between migrants and stayers in the three department categories requires testing whether $\beta_{1}-\beta_{2}=0, \beta_{3}-\beta_{4}=0$, and $\beta_{5}=0$, respectively. Two-sided test results - presented in column 1 in Table 3 - are as follows. First, in the last 27 U.S. departments $\beta_{4}$ is not significantly different from zero, and foreigners are more productive than stayers. Second, the situation is the opposite in the top 25 U.S. departments and the OSC.

As observed in Table 1B, the proportion of young and older people in the three department categories is very different for migrants and stayers. Thus, it appears essential to incorporate vintage effects in model 3. ${ }^{14}$ This is what we do in what we call the final specification, whose results for the key variables in the total sample appear

14. We thank a referee for pointing this out. 
TABLE 3

Two-Sided Tests of Hypothesis Concerning Productivity Comparisons Between Foreigners and Stayers

\begin{tabular}{|c|c|c|c|c|}
\hline & \multirow{2}{*}{$\begin{array}{c}\text { Model } 3 \\
\text { Total Sample } \\
\text { (1) }\end{array}$} & \multicolumn{3}{|c|}{ Final Specification } \\
\hline & & $\begin{array}{c}\text { Total Sample } \\
\text { (2) }\end{array}$ & $\begin{array}{c}\text { Elite } \\
\text { (3) }\end{array}$ & $\begin{array}{l}\text { Quantile Regr. } \\
\text { 95th Percentile (4) }\end{array}$ \\
\hline \multicolumn{5}{|l|}{ (A) Dept. categories } \\
\hline 1. Top 25 U.S. departments & No $(0.28)$ & & & \\
\hline Young & & No $(0.54)$ & No $(0.72)$ & No $(0.42)$ \\
\hline Old & & Yes (0.09) & No $(0.26)$ & No $(0.46)$ \\
\hline 2. Last 27 U.S. departments & Yes $(0.03)$ & & & \\
\hline Young & & Yes $(0.04)$ & No $(0.91)$ & No $(0.40)$ \\
\hline Old & & Yes $(0.03)$ & No $(0.87)$ & No $(0.59)$ \\
\hline 3. 29 OSC departments & No $(t$ statistic $)=1.67)$ & & & \\
\hline Young & & No $(0.33)$ & No $(0.25)$ & No $(0.28)$ \\
\hline Old & & No $(t$ statistic $=1.65)$ & No $(t$ statistic $=1.80)$ & No $(t$ statistic $=0.31)$ \\
\hline \multicolumn{5}{|l|}{ (B) Department categories } \\
\hline \multicolumn{5}{|l|}{ 1. Top 10 U.S. departments } \\
\hline Young & & No $(0.56)$ & No $(0.97)$ & \\
\hline Old & & Yes $(0.04)$ & No $(0.14)$ & \\
\hline \multicolumn{5}{|l|}{ 2. Next 15 U.S. departments } \\
\hline Young & & No $(0.44)$ & No $(0.40)$ & \\
\hline Old & & No $(0.11)$ & No $(0.36)$ & \\
\hline \multicolumn{5}{|l|}{ 3. Last 27 U.S. departments } \\
\hline Young & & Yes $(0.02)$ & No $(0.70)$ & \\
\hline Old & & Yes $(0.02)$ & No $(0.67)$ & \\
\hline \multicolumn{5}{|l|}{ 4. Canada + UK departments } \\
\hline Young & & No $(0.14)$ & No $(0.83)$ & \\
\hline Old & & No $(0.91)$ & Yes $(0.07)$ & \\
\hline \multicolumn{5}{|l|}{ 5. Other OSC departments } \\
\hline Young & & No $(0.74)$ & Yes $(0.06)$ & \\
\hline Old & & No $(t$ statistic $=0.71)$ & No $(t$ statistic $=0.08)$ & \\
\hline
\end{tabular}

Notes: The total sample consists of faculty members with at least one publication in the top 81 departments worldwide according to the Econphd (2004) university ranking, while the elite consists of individuals with above average productivity. Final specification for the total sample and the elites (Productivity measure $=Q$ index, Young if Exp $\leq 20$, and Old if Exp $>20$ ). Hypothesis testing, results: Yes $=$ foreigners are more productive than stayers; No $=$ foreigners and stayers are equally productive; $p$ values in brackets.

in Table 4 (for complete results, see Table 4 in Albarrán, Carrasco, and Ruiz-Castillo 2016). The following three points should be noted.

First, among control variables all demographic variables are significant. However, in the presence of interactions between the variable Young and foreigners and stayers in all department categories, we must differentiate between cohort effects for young foreigners and young stayers in each case. Experience effects are of the same order of magnitude as we have found in previous specifications. As expected, cohort effects for both foreigners and stayers are greater in the top 25 U.S. departments than in the last two bottom department categories. Moreover, cohort effects are greater for foreigners than for stayers in each department category (for detailed results, see Table B.2 in Appendix I in Albarrán, Carrasco, and RuizCastillo 2016). However, the only significant variables among the other control variables are the same three we have found in previous specifications. The adjusted $R^{2}$ in the final specification is 0.551 .

Second, as observed in Table 4, 10 of the 13 variables describing the two cohorts of movers and stayers in the three department categories are significant. For our purposes, the following result should be emphasized: the productivity of both young and older stayers in the last 27 U.S. departments is indistinguishable from the productivity of the reference group, namely OSC older stayers. Instead, the productivity of migrants is hierarchically ordered in the top 25 U.S. departments, the last 27 U.S. departments, and the 29 OSC departments ( $p$ values for the productivity comparisons between foreigners in the last 27 U.S. departments and the OSC are equal to 0.123 for the young and 0.055 for the older individuals). Consequently, the standing of the bottom U.S. 
TABLE 4

Final Specification for the Total Sample and the Elite

\begin{tabular}{|c|c|c|c|c|}
\hline \multicolumn{5}{|c|}{ Dependent Variable: $\log Q$} \\
\hline & \multicolumn{4}{|c|}{ Final Specification } \\
\hline & \multicolumn{2}{|c|}{ Total Sample } & \multicolumn{2}{|c|}{ Elite } \\
\hline & Coeff. & $t$ Statistic & Coeff. & $t$ Statistic \\
\hline 1. U.S. brain circulation & 1.15 & $2.6^{*}$ & 0.77 & $2.6^{*}$ \\
\hline 2. U.S. top 25 , foreigners, young & 1.43 & $5.1^{*}$ & 0.40 & $3.4^{*}$ \\
\hline 3. U.S. top 25 , foreigners, old & 1.11 & $5.6^{*}$ & 0.44 & $5.1 *$ \\
\hline 4. U.S. top 25 , stayers, young & 1.32 & $4.2^{*}$ & 0.35 & $2.0^{*}$ \\
\hline 5. U.S. top 25 , stayers, old & 0.77 & $3.0^{*}$ & 0.29 & $2.0 *$ \\
\hline 6. U.S. last 27 , foreigners, young & 0.91 & $3.3^{*}$ & 0.25 & $2.1 *$ \\
\hline 7. U.S. last 27 , foreigners, old & 0.65 & $3.1^{*}$ & 0.15 & $2.0^{*}$ \\
\hline 8. U.S. last 27 , stayers, young & 0.52 & 1.7 & 0.23 & 1.4 \\
\hline 9. U.S. last 27 , stayers, old & 0.10 & 0.4 & 0.12 & 0.8 \\
\hline 10. OSC brain circ. & 0.59 & $2.7 *$ & 0.24 & $2.7 *$ \\
\hline 11. OSC foreigners, young & 0.73 & $3.0 *$ & 0.23 & $2.0^{*}$ \\
\hline 12. OSC foreigners, old & 0.27 & 1.6 & 0.12 & 1.8 \\
\hline 13. OSC stayers, young & 0.57 & $2.4^{*}$ & 0.12 & 1.1 \\
\hline 14. OSC stayers, old, reference group & - & - & - & - \\
\hline Constant & 1.18 & $8.6^{*}$ & 5.46 & $22.7 *$ \\
\hline$N$ & \multicolumn{2}{|c|}{2,530} & \multicolumn{2}{|c|}{833} \\
\hline Adjusted $R^{2}$ & \multicolumn{2}{|c|}{0.551} & \multicolumn{2}{|c|}{0.317} \\
\hline
\end{tabular}

Notes: The total sample consists of faculty members with at least one publication in the top 81 departments worldwide according to the Econphd (2004) university ranking, while the elite consists of individuals with above average productivity. In all cases, productivity is measured according to the $Q$ index, and an individual is Young if Experience $\leq 20$, and Old if Experience $>20$.

* Significant at the $95 \%$ confidence level.

departments is maintained thanks to the productivity of its foreign faculty. ${ }^{15}$

Third, test results concerning the six productivity comparisons between foreigners and stayers are as follows (column 2 in Table 3): (1) in the top U.S. category, only older migrants are more productive than stayers; (2) in the bottom U.S. category, both young and older migrants are more productive than stayers, and (3) in the OSC, the productivity of both cohorts of migrants is indistinguishable from the productivity of stayers.

\section{B. Results for the Elite}

As indicated in the Introduction, the mixed evidence found in the literature concerning productivity comparisons between migrants and stayers in the United States for samples of different nature and different size suggests analyzing the question using different quality thresholds in our case. Consequently, we study whether the

15. It would be interesting to know whether the large share of economists who are migrants in the last 27 U.S. Economics departments, as well as their productivity differential relative to stayers, are maintained in the next layer of less productive U.S. institutions. results in the total sample are maintained in the elite consisting of 833 economists with above average productivity.

Descriptive statistics are in the right-hand side of Table 1A. Four points should be noted. First, the proportion of young people for all cohort definitions decreases: relative to the total sample, old people are overrepresented in the elite. Second, relative to the total sample the proportion of U.S. stayers (mostly in the top 25 U.S. departments) increases, whereas the proportion of migrants in the United States remains constant. Third, the proportion of people of all sorts working in 2007 the OSC - brain circulation, migrants and stayers - decreases. Finally, the proportions of migrants in the three department categories are the following: $35.0 \%$ in the top U.S. departments, $40.6 \%$ in the bottom U.S. departments, and $29.4 \%$ in the OSC.

Regression results for the key variables in the elite appear in the last two columns in Table 4 (for complete results, see Table 3 in Albarrán, Carrasco, and Ruiz-Castillo 2016). Among demographic variables, the following two points should be noted. First, among experience and cohort variables only Exp is significant. In any 
case, the size of experience effects in the elite is much smaller than in the total sample. Two factors might help explain this pattern: (1) a stronger taste for "puzzle solving," peer recognition, and monetary rewards for top researchers produces a flattening of the productivity profile (Levin and Stephan 1991), and (2) institutional explanatory variables - such as research funding and promotion policies - may operate differentially across the distribution of scientific performance favoring those on the top (Kelchtermans and Veugelers 2011). Second, the productivity of females - representing $5.4 \%$ of the elite - is still smaller than the productivity of males, but the gender effect is considerably smaller than in the total sample: $15.4 \%$ rather than $57.9 \%$. This is in line with the results of Kelchtermans and Veugelers (2012): although females are significantly less likely to reach top performance first, once they manage to do that the gender bias is considerably reduced. On the other hand, among the other control variables, only earning a Ph.D. in any of the 50 schools different from Harvard and MIT has a negative significant effect relative to earning it in the EU. The adjusted $R^{2}$ is 0.317 , versus 0.551 in the total sample.

Intuitively, increasing the quality threshold and reducing the sample size, would tend to make elite members more homogeneous among each other in each of the three department categories we have been studying. As a matter of fact, our extension of Hunter, Oswald, and Charlton's (2009) model in Appendix S1 establishes that the higher the quality threshold considered, the closer the average productivity of foreigners and stayers is expected to be. As can be observed in column 3 in Table 3, this is exactly what happens for all comparisons where foreigners were more productive than stayers in the total sample.

\section{ROBUSTNESS AND INTERPRETATION OF THE RESULTS}

\section{A. The Treatment of the Elite}

We begin by exploring the elite's role using quantile regressions. ${ }^{16}$ Our results indicate that the disappearance of the productivity differences between migrants and stayers in the United States is reached at the 95th percentile (Table $\mathrm{C}$ in Appendix I in Albarrán, Carrasco, and RuizCastillo 2016), whereas $p$ values for productivity comparisons are in column 4 in Table 3.

16. We thank a referee for suggesting this possibility.
Of course, quantile regressions use all data in the total sample but apply different weights at observations below and above a given percentile, whereas results for the elite are obtained using exclusively its 833 observations. Recall that the elite includes individuals with above average productivity beyond the 67 th percentile of the $Q$ distribution. Taking into account that the elite productivity distribution is as highly skewed as the total sample distribution, and the mean is located at the 65th percentile, ordinary least squares (OLS) results for the elite are at, approximately, the 88.5th percentile of the original distribution. Thus, using quantile regressions for the total sample or OLS for the elite leads to the same conclusions.

\section{B. The Partition of Departments}

So far, we have distinguished between two department categories in the United States: the top 25 and the last 27 departments. However, in view of the possible existence of department effects within the first category, it appears interesting to explore a partition including the top ten and the next 15 U.S. departments. However, Canada and the UK are English-speaking countries whose higher education systems are closer in governance to the U.S. system than to the systems in the other countries with at least one department in the sample (the Netherlands, Spain, Israel, Sweden, France, Germany, Belgium, Denmark, and China). Therefore, it appears interesting to explore a partition including the eight UK departments and the four Canadian departments in one category, and the remaining 17 departments in the OSC in another. Surprisingly enough, in the total sample the proportion of young and older foreigners in Canada and the UK is considerably greater than in the other four department categories (Table D in Appendix I in Albarrán, Carrasco, and Ruiz-Castillo 2016).

Regression results for the key variables for the total sample and the elite are in Table B in Appendix S1 (complete results are available upon request). We observe that, as expected, there are strong department effects: for migrants and stayers in both cohorts the top 10 , the next 15 , the last 27 U.S. departments, and the other OSC are hierarchically ordered. Moreover, the productivity of economists in Canada and the UK is indistinguishable from the productivity of those in the last 27 U.S. departments.

Results and $p$ values concerning productivity comparisons between migrants and stayers are in Panel B in Table 3. Three points should be noted. 
First, the main novelty is that the productivity difference between older migrants and older stayers in the top 25 U.S. departments in the previous partition is seen to be essentially due to the situation in the top 10 U.S. departments. Second, it is important to emphasize that, as before, all significant productivity differences in the United States in the total sample vanish when we move to the elite. This is in spite of the fact that the proportion of young and older foreigners in the bottom U.S. departments in the elite is considerably above average. Third, there are two exceptions to the similarity between foreigners and stayers in the elite. The first one is among the old in Canada and the UK, where there is an above average proportion of foreigners (Table D in Appendix I in Albarrán, Carrasco, and Ruiz-Castillo 2016). The second exception is among the small group of 27 young economists in other OSC.

Given these results, for the sake of simplicity we continue the analysis restricting the attention to the partition of the 81 departments into only three categories.

\section{The Definition of the Two Cohorts}

Based on the analysis in Section III.A, so far we have considered young individuals with $\operatorname{Exp} \leq 20$. Next, we must study the robustness of our results to alternative definitions, namely, when $\operatorname{Exp} \leq 15$ and Exp $\leq 24$. Demographic effects, the significance of other control variables and the adjusted $R^{2}$ in the total sample and the elite is of the same order of magnitude for the three cohort definitions. Moreover, since differences in the key productivity comparisons are minor, there are no reasons to depart from our preferred specification where Young $=1$ if Exp $\leq 20$ (for a detailed analysis, see Section IV.3 in Albarrán, Carrasco, and Ruiz-Castillo 2016).

\section{The Measurement of Individual Productivity}

So far, we have used index $Q$ as our productivity measure. In this subsection, we explore the robustness of our results when we use index $Q^{\prime}$, characterized by smaller weights for top journals, and index $P$, namely, the unweighted number of publications of all sorts. The $p$ values for productivity comparisons are in Table 5 (regression results for the key variables for the total sample and the elite are available in Table $\mathrm{G}$ in Appendix I in Albarrán, Carrasco, and Ruiz-Castillo 2016).

Results concerning productivity comparisons between foreigners and stayers under index $Q^{\prime}$ coincide with those obtained under index $Q$. However, using the unweighted number of publications breaks up the unanimous agreement concerning the superiority of foreigners over stayers in the last 27 U.S. departments in the total sample: young foreigners and stayers are now indistinguishable. Moreover, contrary also to all previous results, young migrants are more productive than young stayers in the OSC in the elite. We conclude that, as long as we recognize the merit of publishing in more prestigious

\section{TABLE 5}

Two-Sided Tests of Hypothesis Concerning Productivity Comparisons Between Foreigners and Stayers for Different Productivity Measures

\begin{tabular}{|c|c|c|c|c|}
\hline & \multicolumn{4}{|c|}{ Productivity Measures } \\
\hline & \multicolumn{2}{|c|}{$Q^{\prime}$ Index } & \multicolumn{2}{|c|}{$P$ Index } \\
\hline & Total Sample & Elite I & Total Sample & Elite I \\
\hline \multicolumn{5}{|c|}{ 1. Top 25 U.S. departments } \\
\hline Young & No $(0.59)$ & No $(0.51)$ & No $(0.81)$ & No $(0.96)$ \\
\hline Old & No $(0.10)$ & No $(0.12)$ & No $(0.24)$ & No $(0.40)$ \\
\hline \multicolumn{5}{|c|}{ 2. Last 27 U.S. departments } \\
\hline Young & Yes $(0.06)$ & No $(0.68)$ & No $(0.51)$ & No $(0.32)$ \\
\hline Old & Yes $(0.03)$ & No $(0.68)$ & Yes $(0.07)$ & No $(0.96)$ \\
\hline \multicolumn{5}{|c|}{ 3. 29 OSC departments } \\
\hline Young & No $(0.34)$ & No $(0.15)$ & No $(0.82)$ & Yes $(0.08)$ \\
\hline Old & No $(t$ statistic $=1.63)$ & No $(t$ statistic $=1.51)$ & No $(t$ statistic $=0.37)$ & No $(t$ statistic $=-0.78)$ \\
\hline
\end{tabular}

Notes: The total sample consists of faculty members with at least one publication in the top 81 departments worldwide according to the Econphd (2004) university ranking. Total sample (an individual is Young if Experience $\leq 20$, and Old if Experience $>20$ ). Hypothesis testing, results: Yes $=$ foreigners are more productive than stayers; No = foreigners and stayers are equally productive; $p$ values in brackets. 
journal classes, our results are robust to different weighting schemes.

\section{E. A Plausible Interpretation}

In a world of decreasing transportation, communication, and migration costs of all sorts we should expect the convergence between the average productivity of foreigners and stayers (Hunter, Oswald, and Charlton 2009). This is what we find in the total sample for the young people in the top 25 U.S departments (representing $18.8 \%$ of the population), older people in the intermediate 15 U.S. departments (representing 8.6\%), and in both cohorts in the OSC (representing $26.4 \%$ of the total).

However, this is not the case for some groups (i.e., older people in the top ten U.S. departments, and both cohorts in the bottom U.S. departments) in the total sample. How should we interpret these findings? One possibility is that migration per se is a cause of superior performance, in which case there are positive externalities to be gained by promoting mobile scientists to work with domestic scientists. As pointed out by Franzoni, Scellato, and Stephan (2014), in this case migration is not a zero-sum game in the sense that the benefits that accrue to the destination country do not necessarily come at the expense of the sending country. An alternative interpretation is that the talent distributions under comparison are not the same. Based in the following two considerations, this is the type of explanation we provisionally favor.

Consider first older migrants in our dataset having obtained their Ph.D. in the 1975-1987 period, and having between 50 and 62 years of age in 2007. This subset approximately coincides with the cohorts of foreigners entering the United States between 1975 and 1985 in McDowell and Singell (2000), whose productivity is also greater than the productivity of the corresponding native-born economists. These authors attribute this productivity differential during the period 1975-1989 to the fact that stricter visa requirements for foreigners imposed in 1972 - that is, an increase in mobility costs in Hunter, Oswald, and Charlton's (2009) model — and a poor market for academics beginning in the 1970s may have made Economics departments in that period relatively more selective in their hiring of foreignborn economists.

Next, consider U.S. stayers in the bottom U.S. departments, whose productivity is indistinguishable from the productivity of stayers in the OSC. U.S. nationals have to balance the attraction and costs of an academic career with the opportunities that the U.S. economy offers to highly skilled economists outside academia. Judging from their relatively weak performance, those who choose an academic life at the bottom of the scale are considerably less productive and/or less motivated than those who are able to work at the top 25 departments. Instead, foreigners in the top and bottom U.S. departments appear to be equally motivated to pursue an academic career in the United States. The latter maintain a good performance, just below the former, and essentially above what foreigners exhibit in the OSC.

Joining these two sets of ideas helps in explaining why migrants are more productive than stayers among people older than 50 in the top ten U.S. departments (representing $7.7 \%$ of the total), and among both cohorts in the last 27 U.S. departments (representing 26.5\% of the total).

However, it should be emphasized that, in agreement with our extension of Hunter, Oswald, and Charlton's (2009) model, as soon as we restrict attention to an elite consisting of economists with above average productivity, all productivity differences between migrants and stayers in the United States vanish. This distinction helps to make compatible apparently divergent results in the literature for datasets of scientists of very different size and composition (Hunter, Oswald, and Charlton 2009, vs. McDowell and Singell 2000, and Franzoni, Scellato, and Stephan 2014).

\section{CONCLUSIONS}

In this study, we have measured the individual productivity of a set of 2,530 highly productive economists in terms of a quality index that weights the number of publications from the beginning of everyone's academic career up to 2007 in four journal classes. Individual productivity distributions in all scientific fields are highly skewed regardless of the productivity measure and the size of the population studied. Accounting for such large differences for highly productive economists is the thread that runs throughout the paper. However, we have focused on productivity comparisons between migrants and stayers in 52 U.S. departments and 29 departments in the 11 countries with at least one department in the sample.

Our contributions can be summarized in the following two points. First, controlling for fixed department effects is not enough: productivity 
comparisons between foreigners and stayers must be done within each subgroup of a relevant partition of U.S. departments. Second, confronting foreigners and stayers in a relatively large sample of highly productive scientists or in a small sample of elite scientists in the upper tail of the productivity distribution are different matters. Whether the situation is different in top and bottom institutions, and whether the differences - if any - in larger samples disappear in elite subsets are interesting topics for further research in other scientific disciplines.

At any rate, the superior ex post migrants' performance in some groups and the indistinguishable performance between foreigners and stayers in the remaining groups would tend to confirm the validity of policies aimed at facilitating increased brain exchange across countries (Franzoni, Scellato, and Stephan 2014). We may add that, as long as the concentration of talent in the United States results from the working of a highly competitive market worldwide, efficiency is well served from a global point of view. Furthermore, we should take into account that migrants decide where to live in a voluntary way. However, there are two objections to this view.

First, a number of contributions-written from a European perspective-explain this situation in terms of differences in resources and university governance on both sides of the Atlantic (Ali et al. 2007; Bauwens, Mion, and Thisse 2008; Aghion et al. 2008; Veugelers and Van der Ploeg 2008; Drèze and Estevan 2007; and Section 5.2.1 in Doquier and Rapoport 2012). From this perspective, it might be argued that the degree of concentration of the best talent in the United States constitutes only a second best. Better governance and some additional resources for research institutions in the EU and the RW may give rise to an improved global situation with the highly productive less concentrated in the United States.

Second, other qualified economists question whether the concentration of the best talent working and/or studying in a few U.S. universities has gone too far. On the one hand, Jacques Drèze states: "It is thought provoking that worldwide economic research is being pursued under the leadership of a couple hundred university professors trained and employed by a handful of U.S. departments" (Drèze and Estevan 2007, p. 286). On the other hand, Oswald $(2007$, p. 2) has pointed out that great discoveries often come from unconventional ways of thinking. "This makes me believe that dropping so many of
Planet Earth's scientists into the same American part of the globe may make them worryingly homogeneous. Such intellectual homogeneity could, in the long run, be bad for scientific knowledge and thus for human welfare on our planet."

We should close this discussion indicating that, needless to say, immigration/emigration and other policy recommendations requires studying the results from more representative samples, including the high skilled working outside the academic sector, as well as the low-skilled migrants. This should incorporate the recent literature on immigration emphasizing different channels through which sending countries may benefit from international mobility in a context of increasing globalization. However, progressing in these directions is beyond the scope of this study.

\section{REFERENCES}

Aghion, P., M. Dewatripont, C. Hoxby, A. Mas-Colell, and A. Sapir. Higher Aspirations: An Agenda for Reforming European Universities, Vol. V, Bruegel Blueprint Series, 2008.

Albarrán, P., R. Carrasco, and J. Ruiz-Castillo. "The Elite in Economics.” Working Paper No. 14-14, Universidad Carlos III, 2014. Accessed December 21, 2016. http:// hdl.handle.net/10016/19151.

- "Are Migrants More Productive Than Stayers? Some Evidence for a Set of Highly Productive Academic Economists." Working Paper No. 16-12, Universidad Carlos III, 2016. Accessed December 21, 2016. http:// e-archivo.uc3m.es/handle/10016/23424.

Ali, S., G. Carden, B. Culling, R. Hunter, A. Oswald, N. Owen, H. Ralsmark, and N. Snodgrass. "Elite Scientists and the Global Brain Drain." Working Economic Research Papers No. 825, University of Warwick, 2007.

Azoulay, P., J. G. Zivin, and J. Wang. "Superstar Extintion." Quarterly Journal of Economics, 125, 2010, 549-89.

Bauwens, L., G. Mion, and J.-F. Thisse. "The Resistible Decline of European Science." Revision of CORE DP 2003/11, 2008.

Borjas, G. "The Economic Analysis of Immigration," in Handbook of Labor Economics, edited by O. Ashenfelter and D. Card. Amsterdam: Elsevier, 1999.

Borjas, G., and B. Bratsberg. "Who Leaves? The Outmigration of the Foreign-Born." Review of Economics and Statistics, 78, 1996, 165-76.

Borjas, G., and K. Doran. "Which Peers Matter? The Relative Impacts of Collaborators, Colleagues, and Competitors." Review of Economics and Statistics, 97, 2015, 1104-17.

Doquier, F., and H. Rapoport. "Globalization, Brain Drain, and Development." Journal of Economic Literature, 50, 2012, 681-730.

Drèze, J., and F. Estevan. "Research and Higher Education in Economics: Can We Deliver the Lisbon Objectives?" Journal of the European Economic Association, 5, 2007, 271-304.

Dubois, P., J.-C. Rochet, and J.-M. Schlenker. "Productivity and Mobility in Academic Research: Evidence from Mathematicians." Scientometrics, 98, 2014, 1669-701.

Econphd.net rankings. "Rankings." 2004. Accessed December 21, 2016. http://econphd.econwiki.com/rank/rallec .htm. 
Franzoni, C., G. Scellato, and P. Stephan. "The Movers' Advantage: The Superior Performance of Migrant Scientists.” Economics Letters, 112, 2014, 89-93.

Grogger, J., and G. Hanson. "Attracting Talent: Location Choices of Foreign-Born PHDS in the U.S." NBER Working Paper Series No. 18780, 2013. Accessed December 21, 2016. http//www.nber.org/papers/w 18780 .

Han Kim, E., A. Morse, and L. Zingales. "Are Elite Universities Losing their Competitive Edge?" Journal of Financial Economics, 93, 2009, 353-81.

Hunter, R., A. Oswald, and B. Charlton. "The Elite Brain Drain." The Economic Journal, 119, 2009, F231-51.

Kahn, S., and M. MacGarvie. "How Important Is U.S. Location for Research in Science?" Review of Economics and Statistics, 98, 2016, 397-414.

Kalaitzidakis, P., T. Mamuneas, and T. Stengos. "Rankings of Academic Journals and Institutions in Economics." Journal of the European Economic Association, 1, 2003, 1346-66.

Kelchtermans, S., and R. Veugelers. "The Great Divide in Scientific Productivity: Why the Average Scientist Does Not Exist." Industrial and Corporate Change, 20, 2011, 295-336.

. "Top Research Productivity and Its Persistence." Review of Economics and Statistics, 95, 2012, 273-85.

Kodrzycki, Y. K., and P. Yu. "New Approaches to Ranking Economics Journals." Contributions to Economic Analysis and Policy, 5(1), 2006: article 24.

Laudel, G. "Studying the Brain Drain: Can Bibliometric Methods Help?" Scientometrics, 57, 2003, 215-37.

."Migration Currents Among the Scientific Elite." Minerva, 43, 2005, 377-95.

Levin, S., and P. Stephan. "Research Productivity Over the Life Cycle: Evidence for Academic Scientists." The American Economic Review, 81, 1991, 114-32.

Lubrano, M., L. Bauwens, A. Kirman, and C. Protopopescu. "Ranking Economics Departments in Europe: A Statistical Approach." Journal of the European Economic Association, 1, 2003, 1367-401.

McDowell, J., and L. Singell. "Productivity of Highly Skilled Immigrants: Economists in the Postwar Period." Economic Inquiry, 38, 2000, 672-84.

Nosek, B. A., J. Graham, N. M. Lindner, S. Kesebir, C. B. Hawkins, C. Hahn, K. Schmidt, M. Motyl, J. Joy-Gaba,
R. Frazier, and E. R. Tenney. "Cumulative and CareerStage Citation Impact of Social-Personality Psychology Programs and Their Members." Personality and Social Psychology Bulletin, 36, 2010, 1283-300.

Oswald, A. "Thinking Globally About Science and the UK's Missing 56\% of Elite Scientists". Mimeo, 2007.

Oyer, P. "Initial Labor Market Conditions and Long-Term Outcomes for Economists." Journal of Economic Perspectives, 20, 2006, 143-60.

Panaretos, J., and C. Malesios. "Influential Mathematicians: Birth, Education, and Affiliation." Notices of the American Mathematical Society, 59, 2012, 274-86.

Ruhose, J., M. Parey, F. Waldinger, and N. Netz. "The Selection of High-Skilled Migrants." Beiträge zur Jahrestagung des Vereins für Socialpolitik, 2015. Accessed December 21, 2016. http://hdl.handle.net/ $10419 / 113148$

Ruiz-Castillo, J., and R. Costas. "The Skewness of Scientific productivity." Journal of Informetrics, 8, 2015, 917-34.

Scott, C. E., and J. J. Siegfried. "American Economic Association Universal Academic Questionnaire Summary Statistics.” American Economic Review, 98, 2008, $630-33$.

Stark, O. "The New Economics of Brain Drain." World Economics, 6, 2005, 137-40.

Stephan, P., and S. Levin. "Exceptional Contributions to U.S. Science by the Foreign-Born and Foreign Educated." Population Research and Policy Review, 20, 2001, 59-79.

Veugelers, R., and F. Van der Ploeg. "Reforming European Universities: Scope for an Evidence-Based Process," in Governance of European Universities, edited by M. Dewatripont and F. Thys-Clement, 2008.

Waldinger, F. "Peer Effects in Science: Evidence from the Dismissal of Scientists in Nazi Germany." Review of Economic Studies, 79, 2012, 838-61.

\section{SUPPORTING INFORMATION}

Additional Supporting Information may be found in the online version of this article:

Appendix S1. Statistical material and Hunter, Oswald, and Charlton's (2009) model 